Z. Zellforsch. 114, 22-37 (1971)

(C) by Springer-Verlag 1971

\title{
Fine Structure of Tarsal Sensilla in the Tick Amblyomma americanum (L.)*
}

R. F. Foelix and R. C. Axtell**

Department of Entomology, North Carolina State University, Raleigh, N.C. 27607, U.S.A.

Received October 12, 1970

* This research was supported in part by the Office of Naval Research, and by NIH Training grant ES 00069. Paper no. 3303 of the Journal Series of the North Carolina State University Agricultural Experiment Station, Raleigh.

** The authors thank Dr. Eleanor H. Slifer for valuable discussions and for reviewing of the manuscript. 
Summary. Selected tarsal bristles of the tick Amblyomma americanum (L.) (Acarina: Ixodidae; nymphal stage) were studied by means of scanning and transmission electron microscopy. All sensilla are multi-innervated and have thick cuticular walls containing either an elaborate pore canal system or a single slit opening at the tip. These sensilla, often equipped with two mechanoreceptive dendrites attached to the bristle base, apparently serve a dual function: mechano- and chemoreception. The fine structure of each sensillum is similar to that of other arthropod setae except for the ciliary region of the dendrite. Instead of the common 9 double-tubules, the tick sensilla usually have 11 ("11 +0 "). Compared to insect or spider tarsal bristles, tick setae are less abundant but more complex in structure and of greater variety.

Key-Words: Sensory receptors-Arthropoda-Acarina-Ultrastructure.

Zusammenfassung. Ausgewählte Borsten am Tarsus der Zecke Amblyomma americanum (L.) (Acarina; Ixodidae; Nymphenstadium) wurden mit dem Durchstrahlungs- und Rasterelektronenmikroskop untersucht. Alle Sensillen sind mehrfach innerviert; die dicke Cuticulawandung besitzt entweder ein ausgeprägtes Porenkanalsystem oder eine schlitzförmige Öffnung nahe der Spitze. Diese Sensillen haben oft zusätzlich zwei mechanoreceptive Dendriten an der Borstenbasis angeheftet und dienen dann offenbar zwei Funktionen: Mechanound Chemoreception. Die Feinstruktur jedes Sensillums ist ähnlich wie in anderen Arthropodensinneshaaren, mit Ausnahme der Ciliärregion des Dendriten. Statt der herkömm. lichen 9 Doppeltubuli besitzen Zeckensensillen gewöhnlich 11 (" $11+0$ "). Verglichen mit den tarsalen Borsten von Insekten und Spinnen erscheinen Zeckensensillen zwar weniger zahlreich, dafür strukturell komplexer und von größerer Vielfalt.

\section{Introduction}

The first pair of walking legs in ticks is equipped with many sensory structures, and these legs are waved in the air in a manner similar to that of insect antennae (Batelli, 1891). Sensory functions such as chemo-, humidity- and temperaturereception are usually assigned to Haller's organ, or to other specialized bristles on the tarsus (Lees, 1948). The common setae covering the tarsus are mostly referred to as "protecting hairs" (Nuttall et al., 1908) and their function is assumed to be tactile (Schulze. 1942; Lees, 1948; El-Ziady, 1958). Only recently some of the common bristles were believed to be also involved in chemoreception (Zolotarev and Elizarov, 1963; Zolotarev and Sinitsyna, 1965). The present study 
is the first to deal with the fine structure of these common setae on the tarsus of the tick Amblyomma americanum L. (Acarina: Ixodidae) and provides morphological evidence for various sensory functions.

\section{Materials and Methods}

Tarsi of the first legs of $A$. americanum (nymphal stage) were fixed in cold $5 \%$ glutaraldehyde (Sabatini et al., 1963), post-fixed in $1 \% \mathrm{OsO}_{4}$ (Palade, 1952), dehydrated in ethanol and embedded in hard Epon 812 over propylene oxide. Sections were cut on a Reichert Om U2 ultramicrotome with a diamond knife and picked up with Formvar-coated copper grids. The staining procedure involved uranyl acetate (in $50 \%$ ethanol) and lead citrate (Venable and Coggeshall, 1965) for 20-30 minutes each and was performed with the grids held in small plastic-ring carriers to reduce contamination (Locke and Collins, 1965). Doublestained sections were examined in a Siemens Elmiskop 1A at an accelerating voltage of $80 \mathrm{kV}$. The use of wide-meshed grids (100 mesh or slot grids) facilitated orientation and allowed the tracing of specific bristles from the base to their tips.

For light microscopy, semi-thin sections $(0.5 \mu$.) were cut from the same Epon blocks and double-stained with basic fuchsin and azure B-methylene blue (Richardson et al., 1960). These sections were used primarily for orientation purposes.

A JEOL JSM 2 scanning electron microscope (SEM) was very useful for studying bristle distribution and details in surface structure. Material fixed in 5\% glutaraldehyde or whole animals freshly killed in hot water (and without further fixation) were used for the SEM work after coating with gold.

\section{Results}

Specific bristles on the dorsal surface of the tick's tarsus were selected with Haller's organ serving as the reference point. Two setae standing close together distal to Haller's organ (Figs. 1, 2) were termed "distal" bristles" ; two others at the posterior side of Haller's organ were called accordingly "posterior" bristles; a group of four bristles standing further proximal was called the "four-group"2 and a final group of two located close to the metatarsus was referred to as "proximal" bristles. Haller's organ proper was not included in the present study but is the subject of another investigation.

\section{1. "Distal" Bristles}

The two pointed bristles are about $45 \mu$ long and possess a distinct socket. They appear very similar, even under high magnification with the SEM (Fig. 2). However, the bristle $\left(d_{1}\right)$ facing the body is larger $(4 \mu$ diameter at the base) than the one $\left(d_{2}\right)$ pointing to the outside $(3 \mu)$; this difference is consistent in all scanning electron micrographs. The larger bristle actually has a thinner cuticular wall $(0.7 \mu$ at the base) than the other bristle $(0.85 \mu)$; the latter therefore has a reduced, narrow lumen (Figs. 3, 4). The fine structure of the two "distal" bristles differs distinctly and therefore will be discussed separately.

a) Bristle $d_{1}(4 \mu$ diameter; located mesad). Although the cuticle wall appears completely smooth we could detect fine pores at higher magnification in scanning and transmission electron micrographs (Figs. 2, inset; 3a). The pores have an

1 "anterior bristle group" of Lees (1948) and "M 3 " bristles of Zolotarev and Sinitsyna (1965).

2 The "posterior bristle group" of Lees (1948) refers probably to "posterior" bristles plus "four-group". Zolotarev and Sinitsyna (1965) call the "four-group" the "X 6 " bristles but do not indicate the "posterior" bristles in their drawing (p. 20, Fig. 2). 

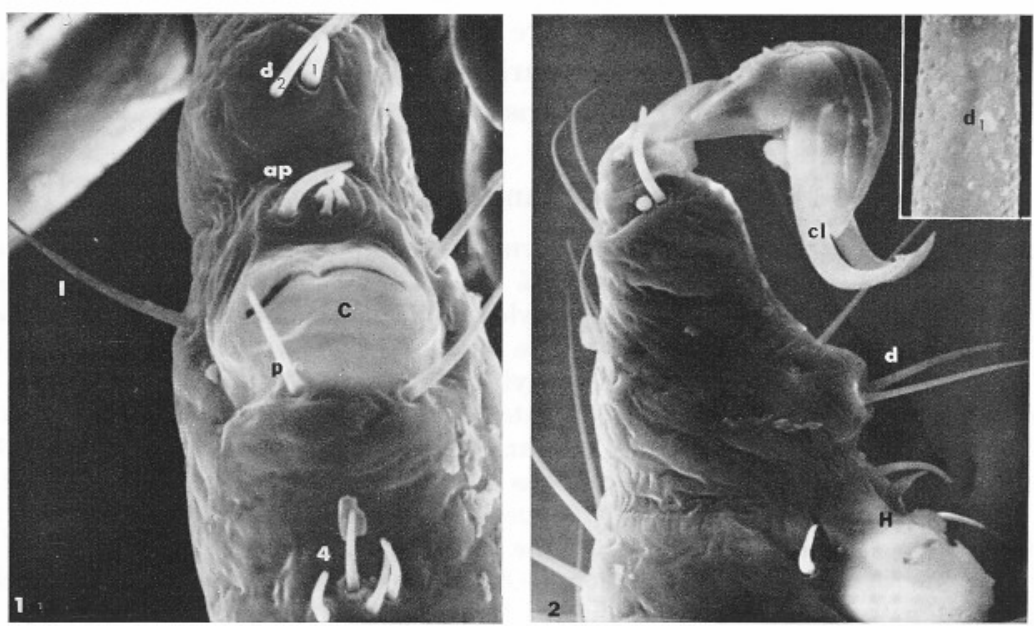

Fig. 1. Dorsal view of tarsus of first leg in the nymph of Amblyomma americanum. Haller's organ, consisting of anterior pit $(a p)$ and capsule $(c)$ in the center. The other sensilla were termed "distal" bristles $(d)$, "lateral" bristles $(l)$, "posterior" bristles $(p)$ and the "four-group" (4). "Proximal" bristles not shown. SEM $\times 500$

Fig. 2. Lateral view of tarsus tip of leg 1 showing claws $(c l)$, two distal bristles $(d)$ and Haller's organ $(H)$. Note that bristles are more numerous on ventral side than dorsally. $\mathrm{SEM} \times 375$. Inset: one of the "distal" bristles $\left(d_{1}\right.$ in Fig. 1$)$ with numerous pores which appear as slight depressions. SEM $\times 10000$

opening that is slightly larger than $0.1 \mu$ and they are spaced at a distance of $0.5-1.0 \mu$. The characteristic feature of the pores is an ovoid, dense body which seems to plug the pore canal (Fig. $3 \mathrm{~b}$ ). This cuticle plug is suspended on the wall of the pore canal, possibly by cuticular strands (Fig. 14b).

The lumen of this seta is fluid-filled and contains five dendrites which begin branching shortly after entering at the hair base (Fig. 5). There is no association between the dendritic branches and the pores in the cuticle wall other than the fluid. At the level of the bristle socket the five dendrites become enclosed by an

Fig. 3. a) Longitudinal section of the larger seta $\left(d_{1}\right)$ of the two distal bristles. The thickwalled cuticle is perforated by many pores; the lumen contains many dendritic branches (d) bathed in a fluid. Note "plug" in one of the pores. (arrow). $\times 16000$. b) A pore at higher magnification showing a dark, lens-shaped body plugging the pore canal. Granular material represents precipitated hemolymph $(h l)$ that filled the bristle lumen. $\times 44000$

Fig. 4. Cross-section of the smaller seta $\left(d_{2}\right)$ of the two distal bristles. The cuticle is very thick and no pores are visible. Note narrow lumen with two unbranched dendrites surrounded by a crescent-shaped scolopale and small canal penetrating cuticle (arrow). No connection to outside was observed. $\times 27000$

Fig. 5. Base of the same bristle as in Fig. 3a. Note dendritic branching (arrows) inside lumen, processes of an enveloping cell attached to the cuticle wall, and layered structure of articulating membrane $(\mathrm{am}) . \times 9800$

Fig. 6. Cross-section of the two distal bristles at level of base. The base of the larger bristle $\left(d_{1}\right)$ located in lower part of micrograph, is entered by 5 dendrites which are surrounded by a dense scolopale. The outer bristle (upper half) contains 2 dendrites $(c)$ passing into the lumen and two mechanoreceptive dendrites $(m)$ connected to the bristle base. $\times 8600$ 

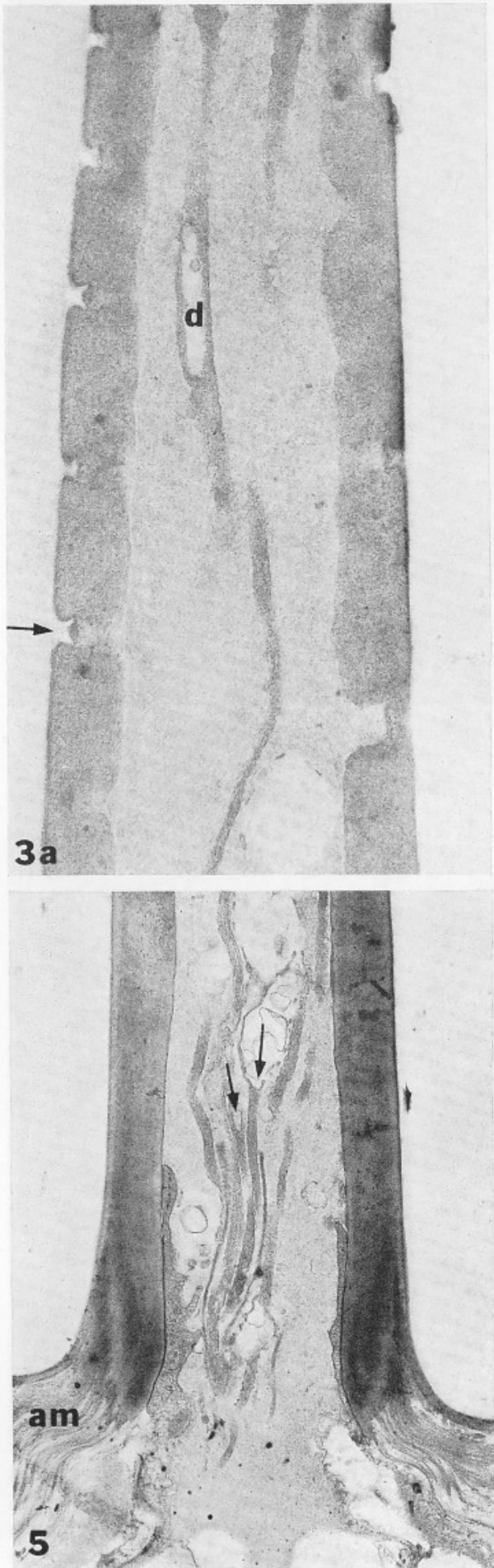
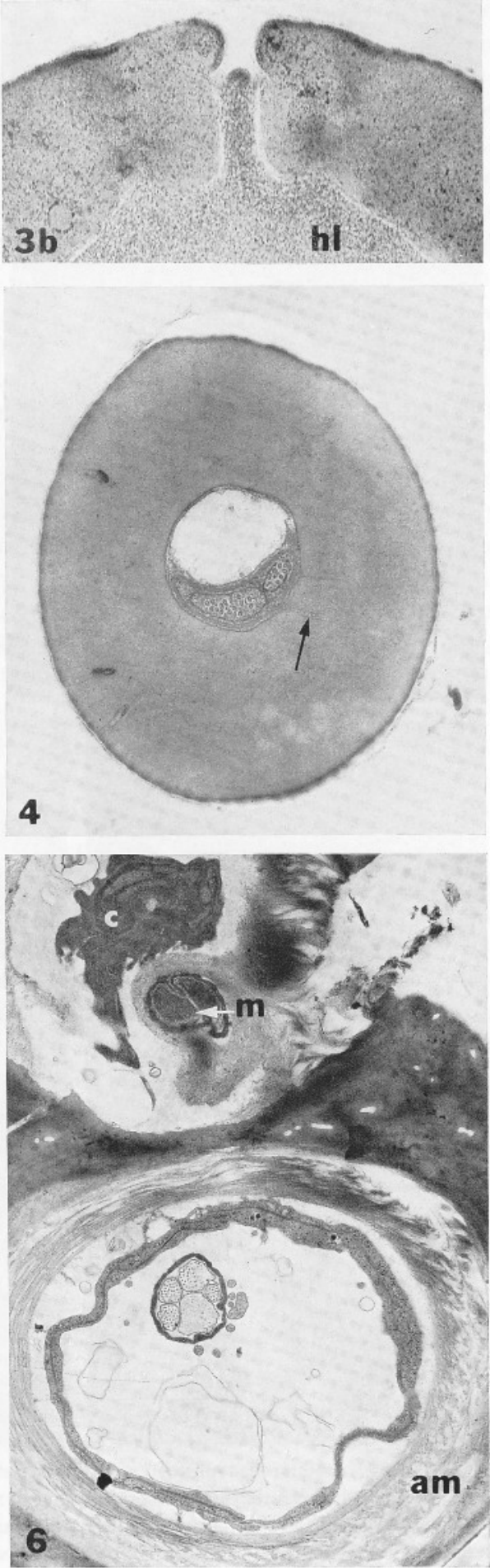

Figs. 3-6 

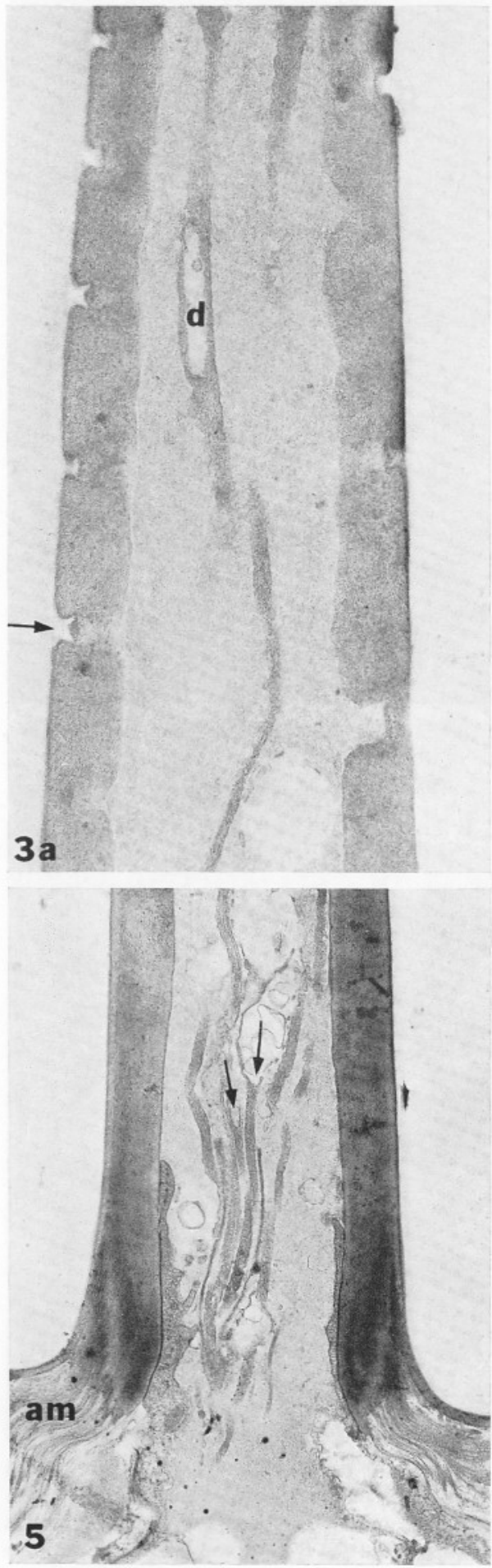
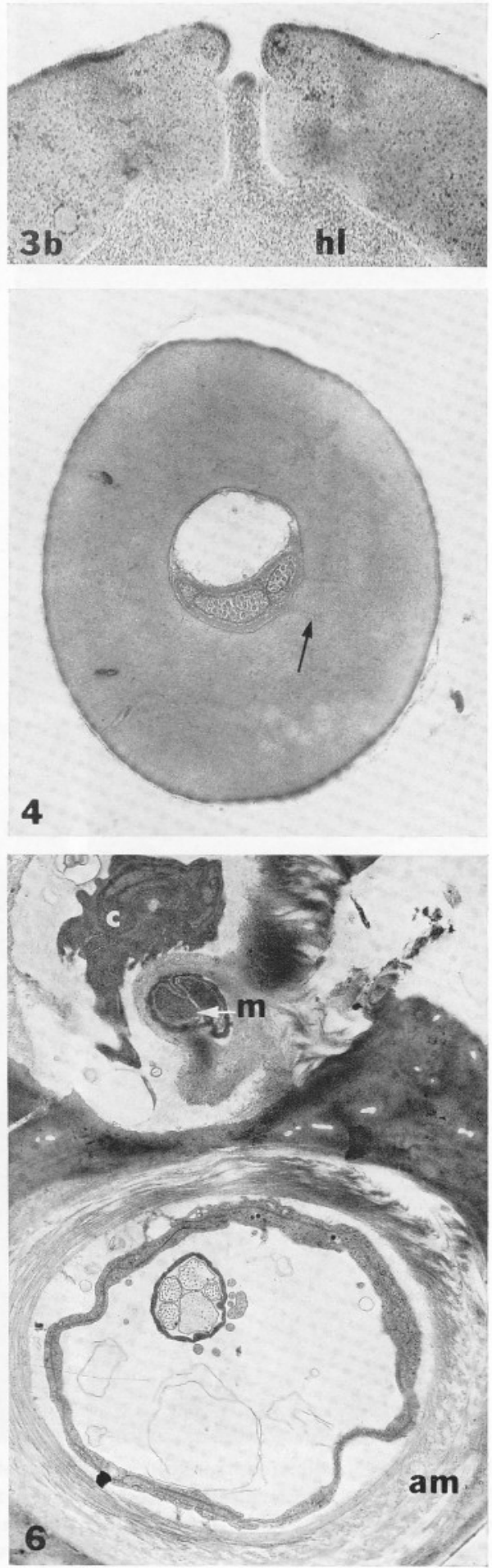

Figs. 3-6 

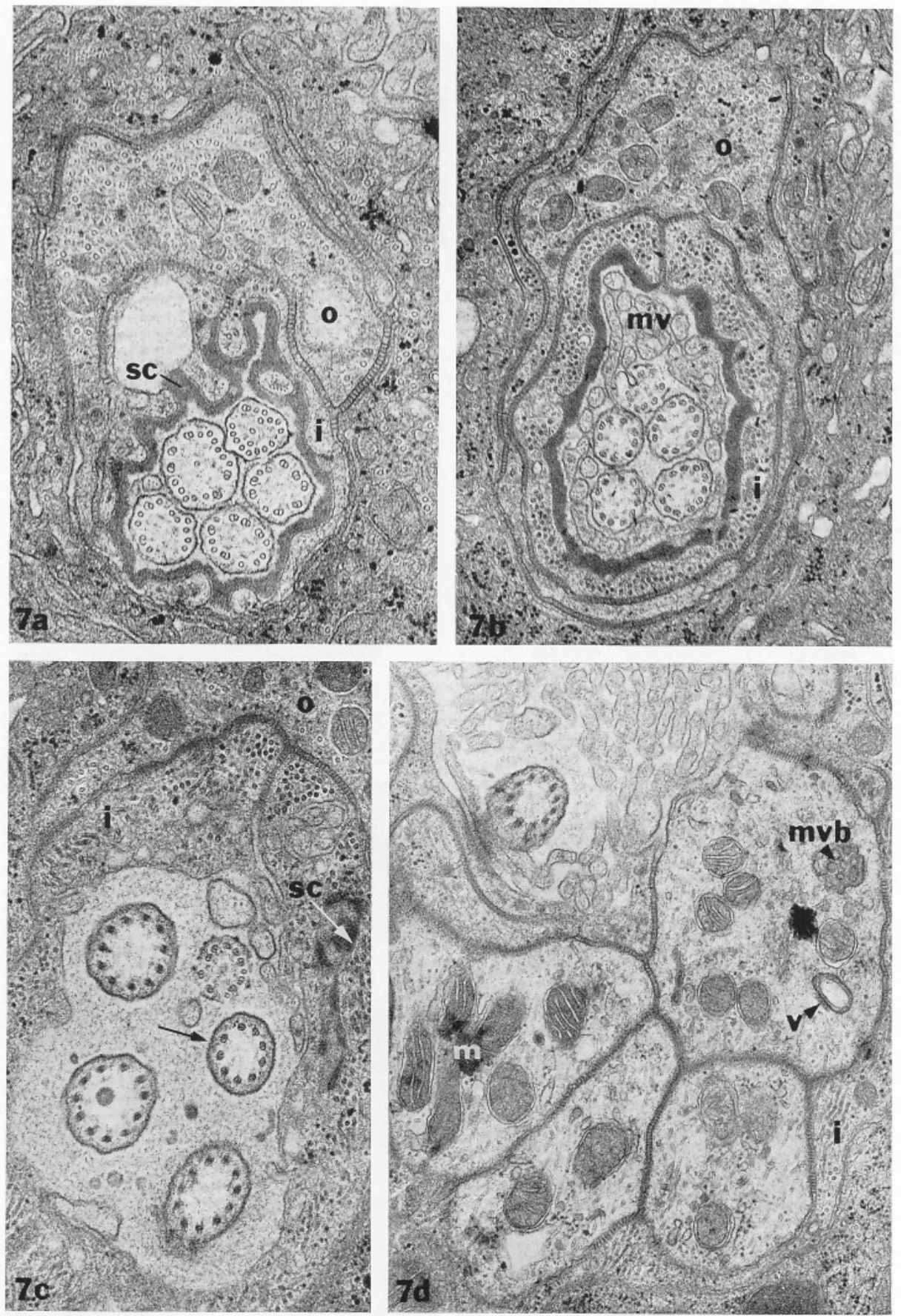

Fig. $7 \mathrm{a}-\mathrm{d}$. Consecutive transverse sections of the neural component of the larger distal bristle $\left(d_{1}\right)$. a) The five outer dendritic segments contain only microtubules, some of which combine to form double-tubules while approaching the ciliary region. The scolopale $(s c)$ is irregularly folded and surrounded by two enveloping cells $(o, i)$ interconnected by septate 
electron-dense sheath, the scolopale (cuticular sheath) (Fig. 6). Following the dendrites further toward the hypodermis we note microvillar extensions of an enveloping cell, a widening of the scolopale and the appearance of some doublemicrotubules in the dendrites (Fig. 7 a). These double-tubules occur only at the periphery while single microtubules gradually disappear. The ciliary region consists mostly of 11 double-tubules (Fig. 7 b, c) and only one dendrite with the common " $9+0$ " formula was found. A dense granule is noted in many cross sections of ciliary regions (Fig. $7 \mathrm{c}$ ) but should not be mistaken with central elements since it is non-tubular. At the point of the ciliary region the scolopale structure terminates and a fluid-filled, extra-cellular space surrounds the five dendrites (Figs. 7 c, 8). An inner and an outer enveloping cell can be distinguished which are interconnected by septate desmosomes. The inner enveloping cell (trichogen cell) is filled by many microtubules running paralled to the axis of the dendrites; the outer enveloping cell (tormogen cell) contains fewer microtubules but many mitochondria. As usual, the ciliary region marks the transition between inner and outer segment of the dendrite (Thurm, 1964). The inner segments (Fig. 7 d) are considerably larger in diameter and possess numerous mitochondria and sometimes rosettes of glycogen. Two basal bodies with rootlets could not be demonstrated in this particular bristle but were found in all other tick sensilla investigated (Fig. 8). Typically, multivesicular bodies are in close proximity to the basal bodies as well as some translucent vesicles, which apparently are the product of pinocytosis. The course of the dendrites was not followed further than the beginning of the inner segments.

b) Bristle $d_{2}(3 \mu$ diameter; laterad; Fig. 1). This bristle possesses two mechanoreceptive endings at the base, in addition to two dendrites entering the lumen (Fig. 6). The two mechanoreceptive dendrites are enclosed by one scolopale which attaches to the socket cuticle (joint membrane). Each dendritic ending contains a dense "tubular body" (Thurm, 1964) which is characteristic of many mechanoreceptors. Two other dendrites ensheathed by a scolopale, invade the narrow bristle lumen and ascend without branching (Fig. 4). Since no distinct pores could be detected in the shaft, it is probable that these dendrites communicate with the outside by means of a single opening close to the tip. All four dendrites of bristle $d_{2}$ have the same ultrastructure as described for bristle $d_{1}$, with the exception that no dendritic branching occurs. Again, the number of double-tubules is 11 rather than 9 or 10. In this seta a basal body could be found, but it was not possible to determine whether the eleven elements are composed of triplets as is usually the case in basal bodies.

desmosomes. $\times 36000$. b) The beginning ciliary region shows two distinct enveloping cells, the dense scolopale and some microvilli $(m v)$ of the inner enveloping cell $(i)$. Only doubletubules are present at the periphery of the dendrite; the dominating tubule number is 11 . $\times 27000$. c) The same ciliary region, slightly more proximal, shows 3 dendrites equipped with 11 double-tubules, one with 9 (arrow) and the smallest with 9 double-tubules plus two single ones. Note that scolopale $(s c)$ has almost disappeared. $\times 28000$. d) In contrast to the outer segment (see a) the inner dendritic segment contains multivesicular bodies $(m v b)$ and electron-lucent vesicles $(v)$ in close proximity to the ciliary region. Many mitochondria $(m)$ occur throughout its entire length. Four beginning inner segments are seen while the fifth segment is still sectioned at the level of the ciliary region. $\times 21000$ 


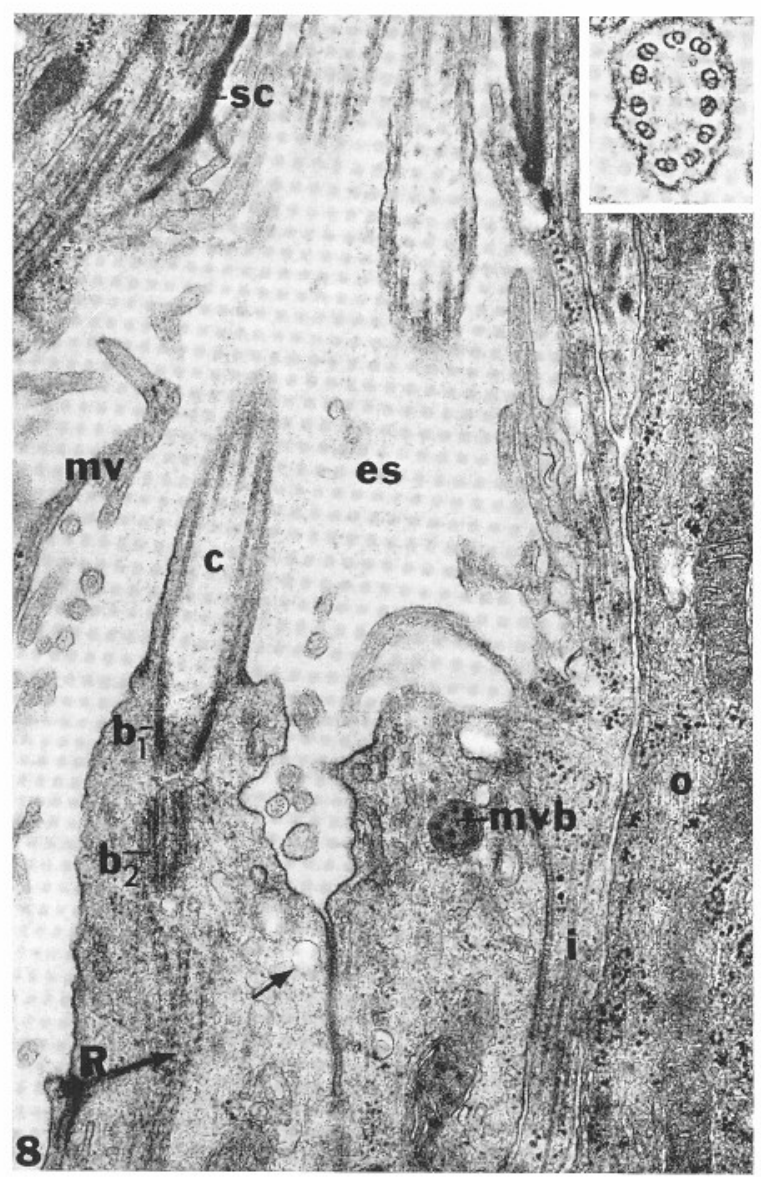

Fig. 8. Innervation of a tarsal tick sensillum (location not determined). Longitudinal section of ciliary region exhibits two basal bodies $\left(b_{1}, b_{2}\right)$ with rootlets $(R)$, multivesicular bodies $(m v b)$ and electron-lucent vesicles (arrow). Two dendrites, surrounded by outer and inner enveloping cell $(o, i)$ can be distinguished. Note oblique section of one of the outer segments (with 11 double-tubules) and termination of scolopale (sc). $m v$, microvilli of inner enveloping cell; es, extra-cellular space, $c$, ciliary region $\times 22000$. Inset: Cross section of ciliary region showing the typical 11 double-tubules. $\times 50000$

\section{2. "Posterior" Bristles}

The two posterior bristles are 35-45 $\mu$ long and measure about $4 \mu$ in diameter at the base. Like the "distal" bristles they insert vertically in a socket in the cuticle, thus being freely movable. No pore openings were noted in the bristle wall when examined with the SEM. Both bristles are almost identical in their fine structure and resemble the $d_{2}$ seta of the "distal" bristles (Fig. 9). Six or seven dendrites, surrounded by an electron-dense fluid and ensheathed by a scolopale, enter the bristle lumen. Additionally, two dendrites enclosed in one scolopale attach eccentrically to the bristle base; their prominent "tubular bodies" characterize them as mechanoreceptors (Fig. 10a). The six or seven other dendrites, 


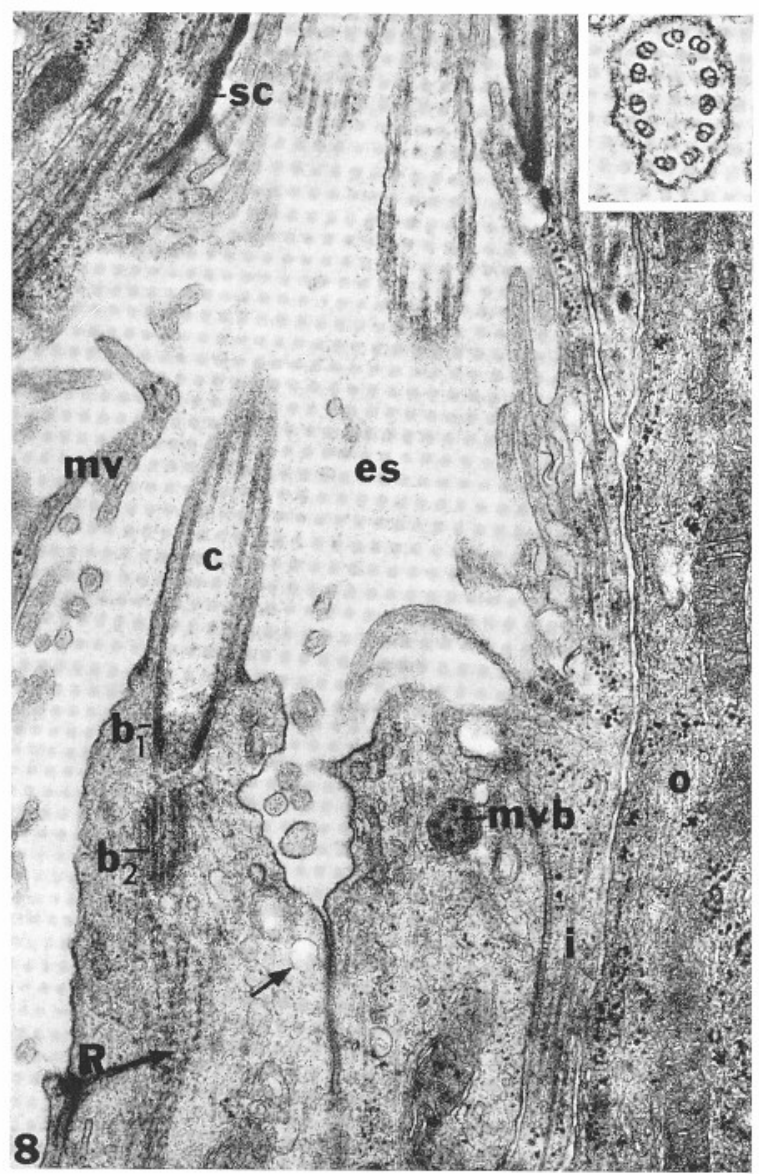

Fig. 8. Innervation of a tarsal tick sensillum (location not determined). Longitudinal section of ciliary region exhibits two basal bodies $\left(b_{1}, b_{2}\right)$ with rootlets $(R)$, multivesicular bodies $(m v b)$ and electron-lucent vesicles (arrow). Two dendrites, surrounded by outer and inner enveloping cell $(o, i)$ can be distinguished. Note oblique section of one of the outer segments (with 11 double-tubules) and termination of scolopale $(s c)$. $m v$, microvilli of inner enveloping cell; es, extra-cellular space, $c$, ciliary region $\times 22000$. Inset: Cross section of ciliary region showing the typical 11 double-tubules. $\times 50000$

\section{2. "Posterior" Bristles}

The two posterior bristles are $35-45 \mu$ long and measure about $4 \mu$ in diameter at the base. Like the "distal" bristles they insert vertically in a socket in the cuticle, thus being freely movable. No pore openings were noted in the bristle wall when examined with the SEM. Both bristles are almost identical in their fine structure and resemble the $d_{2}$ seta of the "distal" bristles (Fig. 9). Six or seven dendrites, surrounded by an electron-dense fluid and ensheathed by a scolopale, enter the bristle lumen. Additionally, two dendrites enclosed in one scolopale attach eccentrically to the bristle base; their prominent "tubular bodies" characterize them as mechanoreceptors (Fig. 10a). The six or seven other dendrites, 


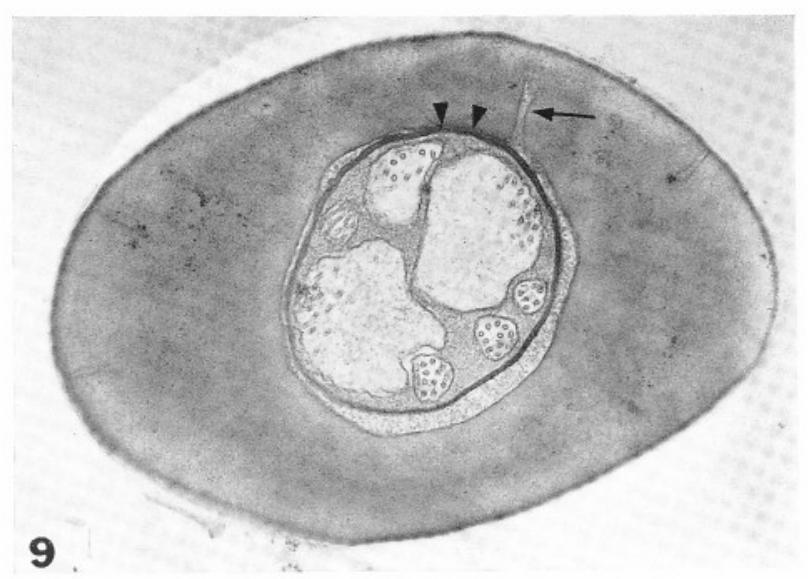

Fig. 9. Cross-section of shaft of a "posterior" bristle. Three of seven dendrites have a swollen appearance which may be a fixation artifact. Scolopale contacts cuticle wall (2 small arrows) while crescent-shaped lumen sends fine canals into the cuticle (arrow). No direct communication to the outside is observed at that level. $\times 23000$

presumably chemoreceptors, pass into the lumen while enclosed by a wide, circular scolopale. No branching occurs while ascending the bristle shaft but some dendrites appeared swollen in diameter (fixation artifact?). Although there are indications of pore canals in the cuticle wall (Fig. 9) no clearly defined pores were visible throughout the shaft. We therefore assume there is a single opening at the tip as was found in the "proximal" bristles.

The site of the eiliary region is the same for all six to seven dendrites and cross-sections of that area show either basal bodies or eleven double-tubules of the beginning outer segment (Fig. 10b). Details with respect to inner and outer dendritic segments, scolopale and sheath cells are the same as for seta $d_{1}$ of the "distal" bristles.

\section{The "4-group"}

All bristles of the "4-group" are structurally very similar but differ distinctly from the "distal" and "posterior" bristles described above. They vary from 22 to $30 \mu$ in length and measure approximately $2.5 \mu$ at the base. The bristle surface is slightly scalloped and bears 5 or 6 grooves running in longitudinal direction. No pore openings could be detected with the SEM. Only one or two dendrites enter the bristle lumen at the base and these do not branch while ascending the shaft. They are surrounded by a wide, thin-walled scolopale which contains a fluid of higher electron density than the normal fluid of the extracellular space (Fig. 11a). On the way toward the bristle tip the circular scolopale increases in thickness and attaches to the cuticle wall of the seta. Hence we can distinguish an inner circular lumen with one or two dendrites bathed in an electron-dense fluid and an outer crescent-shaped lumen with an extra-cellular fluid of relatively lower density (Fig. 11). The scolopale makes contact with the wall at several points thus subdividing the original crescent-shaped lumen into 

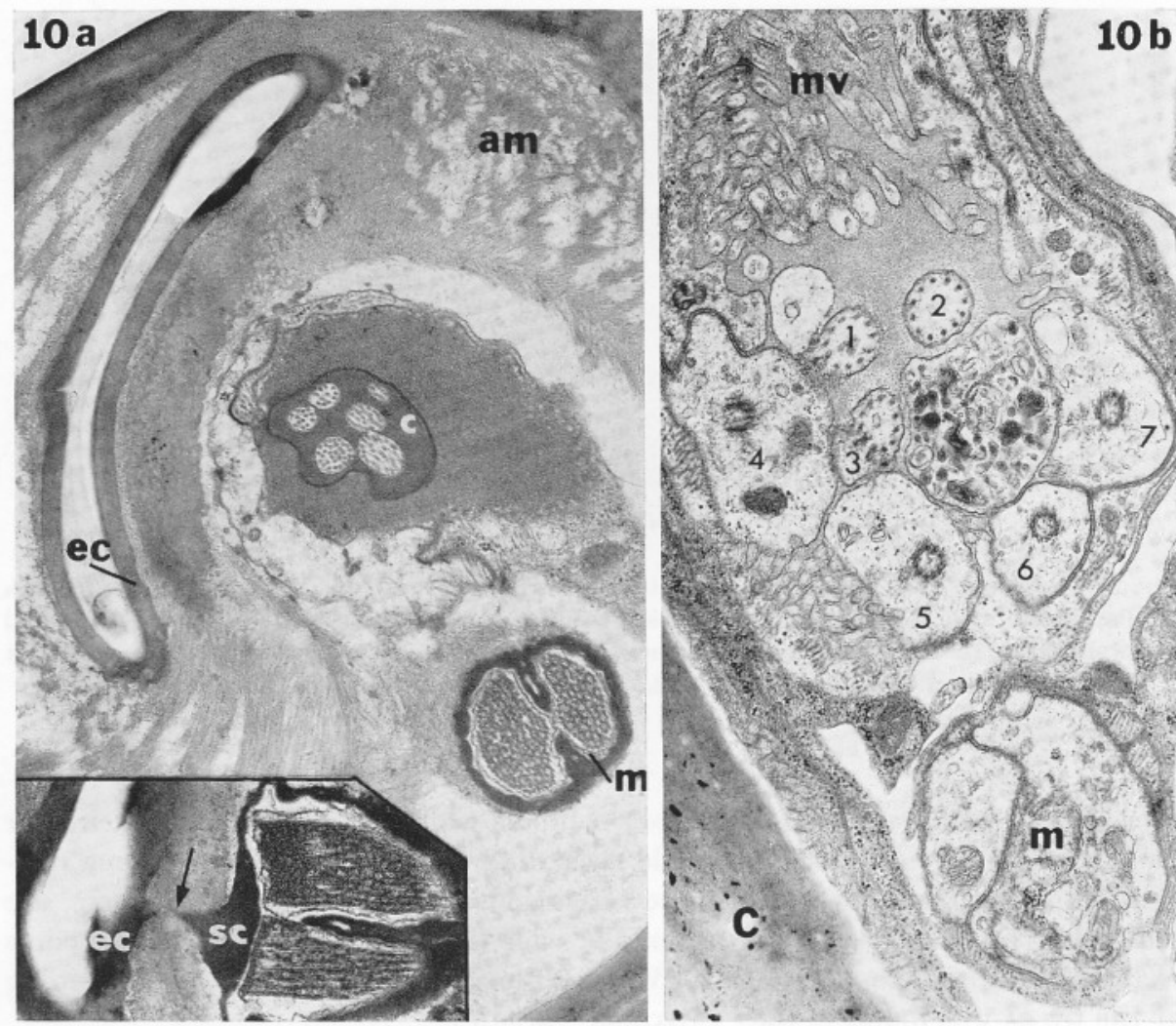

Fig. 10. a) Cross-section of base of a "posterior" bristle. Thick scolopale surrounds two mechanoreceptive dendrites $(m)$, which are both equipped with a prominent tubular body. Six other dendrites $(c)$ are bathed in an electron-dense fluid and enclosed by a thin scolopale. Only these six dendrites pass into the bristle lumen. am, articulating membrane; ec, epiand exocuticle. $\times 14700$. Inset: Longitudinal section of the two mechanoreceptive dendrites. Arrow indicates the continuity between exocuticle $(e c)$ and scolopale $(s c) . \times 17000$. b) Cross-section of neural components of a "posterior" bristle at the level of the ciliary region. Two inner segments of mechanoreceptive dendrites $(m)$ are in the lower right corner. Seven dendrites belong to the bristle lumen: three are sectioned through the ciliary region (1-3) and four show the beginning inner segment each with a basal body (4-7). Note that dendrite number 2 contains 12 double-tubules. $C$, cuticle; $m v$, microvilli of inner enveloping cell. $\times 15500$

several compartments (Fig. 11c). Following the bristle shaft further distally, pores appear, which are so small in size (approx. $100 \AA$ ) that they are beyond the normal resolution of the SEM $(200 \AA)$, but can be seen well in transmission electron micrographs. They are always arranged in a pentagonal or hexagonal pattern and connect the central circular lumen with the grooves on the bristle surface (Fig. 11d). The most conspicuous feature of this bristle type is the form of the pores which can be roughly described as "vase-shaped". The immediate pore opening forms a channel of $100-150 \AA$, widens to a small chamber of 

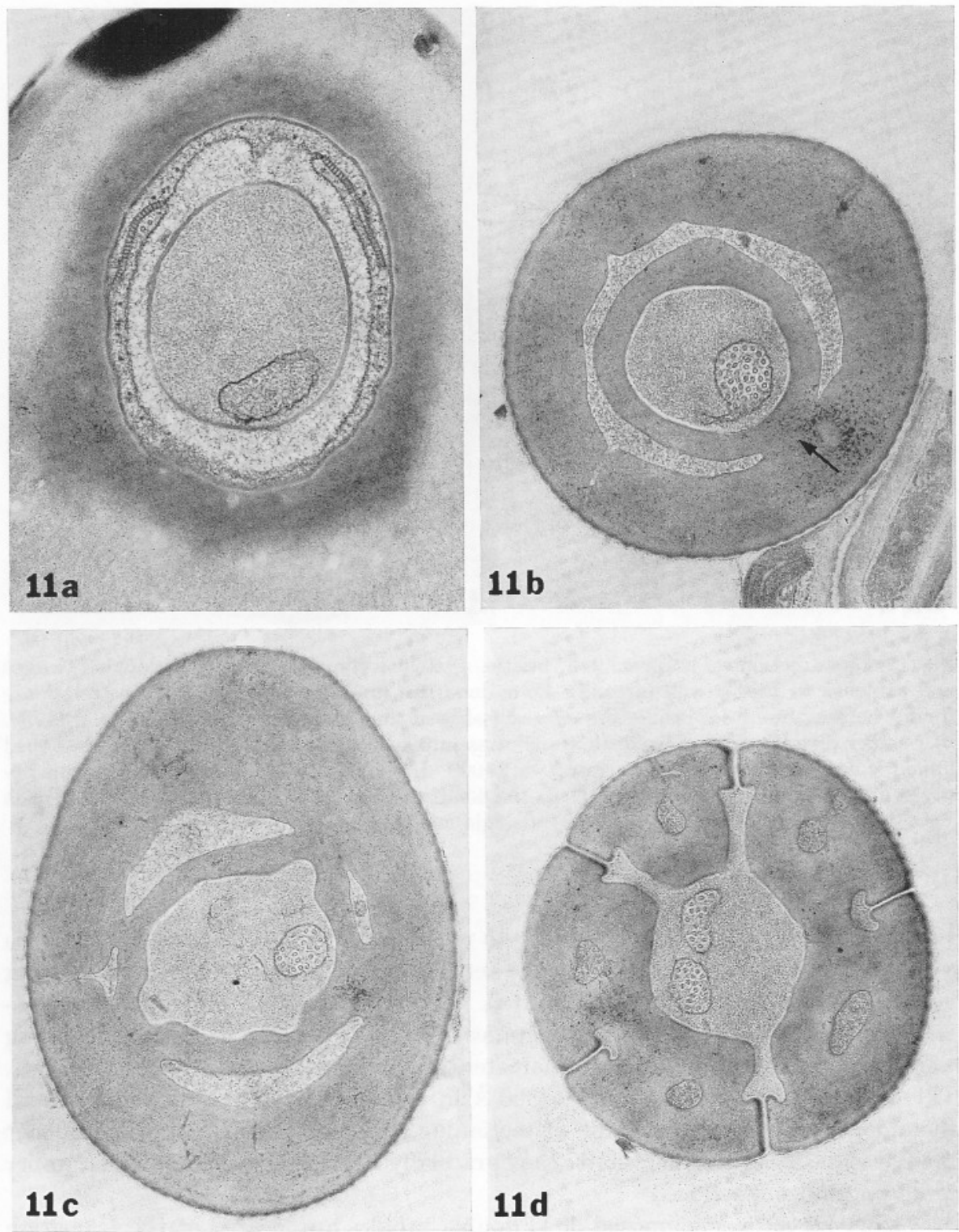

Fig. 11 a-d. Bristles of "four-group" in consecutive cross-sections (from proximal to distal). a) In the basal region a thin circular scolopale surrounds a single dendrite (sometimes two) bathed in an electron-dense fluid. Processes of an enveloping cell, interconnected by septate desmosomes, line the cuticle wall. $\times 29000$. b) Further distally the scolopale becomes replaced by a thick, cuticular ring which contacts the cuticle wall (arrow). Outer, crescent-shaped lumen bears indentations which may indicate the beginning pore system. Some fungal spores are attached to the outside of this bristle shaft. $\times 28500$. c) Cuticular ring attaches at several points to bristle wall. $\times 27000$. d) Cross-section of distal bristle shaft exhibiting pentagonal arrangement of "vase-shaped" pores. Original crescent-shaped lumen becomes reduced to small cylinders standing intermittantly between the pores. This particular bristle contains two dendrites inside the lumen. $\times 27000$ 

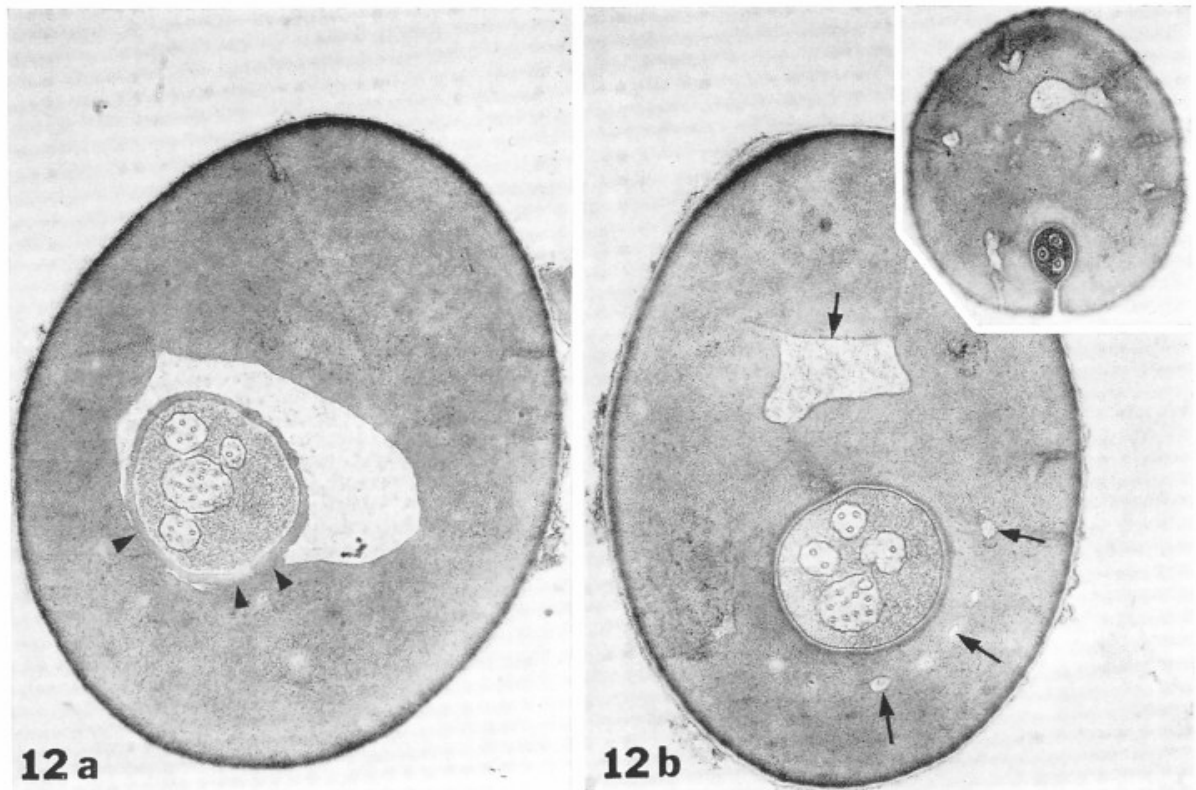

Fig. 12. Cross-sections of a "proximal" bristle. a) Relatively close to base, scolopale thickens and attaches to bristle wall (arrows). Four dendrites are surrounded by an electron-dense fluid whereas the fluid inside the crescent-shaped lumen appears very light. $\times 23700$. b) Further distally, former scolopale transforms into a thick cuticle tube; the crescent-shaped lumen is considerably reduced (arrows). $\times 27000$. Inset: Close to the tip, a narrow slit between circular lumen and outside exposes the dendritic endings to the atmosphere. Note each dendrite has only a single microtubule. $\times 27000$

$1800 \AA$ width in the middle part of the cuticle wall and then narrows again to a channel of $800 \AA$ which opens to the central lumen. Actually, the pore opening is not circular but slit-like (Fig. 14a). This is concluded from many crosssections, all of which show the communication to the outside. If the pore opening were circular and only $100 \AA$ in diameter, it would be missed in most sections. This is true for the inner channel ( $800 \AA$ in diameter) which is cylindrical and therefore often out of the plane of sectioning. The one or two dendrites do not branch while ascending the shaft; they gradually become thinner and the number of microtubules is reduced.

Ciliary structures composed of 11 double tubules are located at the transition zone between the outer and inner dendritic segments. No mechanoreceptor was found at the bristle base, although each seta is suspended in a socket.

\section{4. "Proximal" Bristles}

Two longer setae $(25 \mu)$ stand proximal to the "4-group" and only a few, extremely short sensilla occur on the remaining dorso-proximal part of the tarsus. Like the "posterior" bristles they possess two mechanoreceptive dendrites connected to the base and several (3-4) dendrites entering the lumen. The structure 


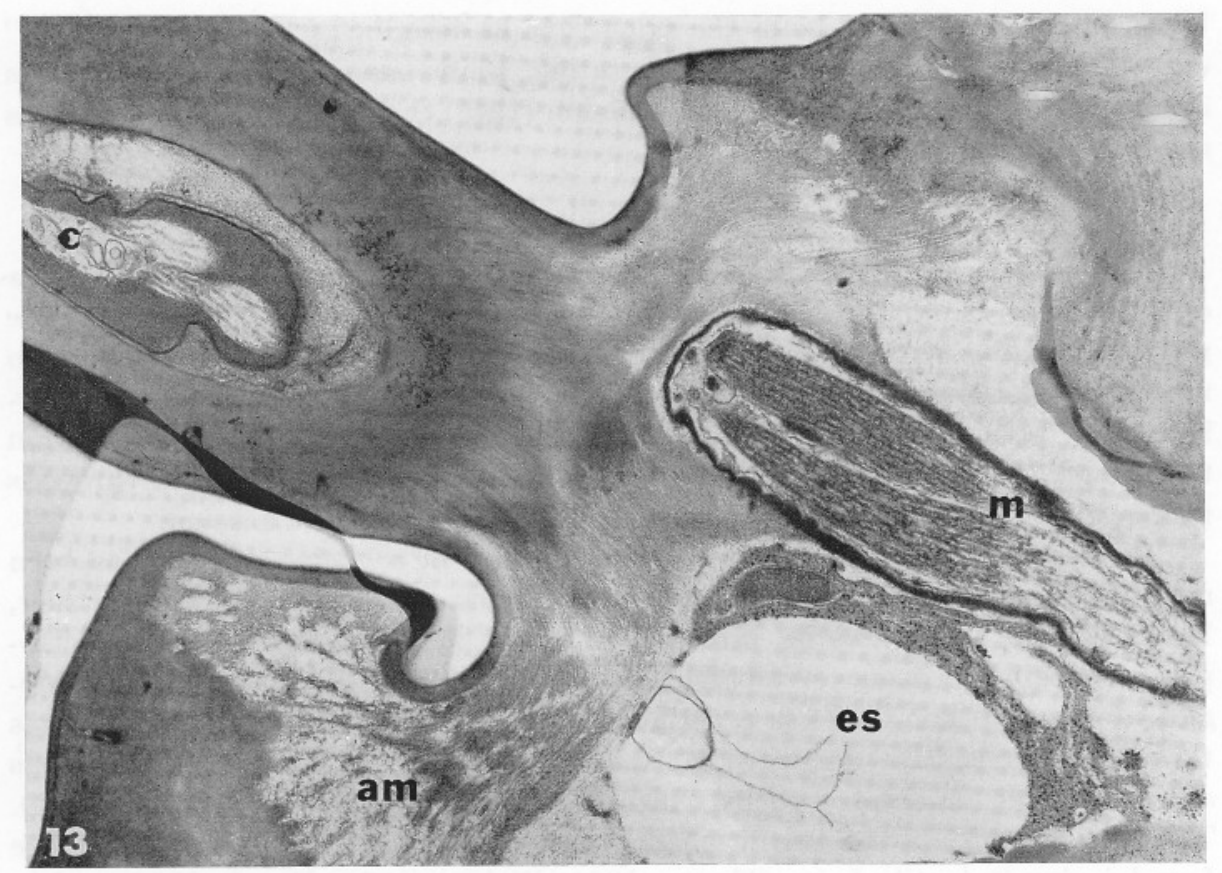

Fig. 13. Para-sagittal section of a "lateral" bristle on the tick's tarsus (see Fig. 1). Note combination of several dendrites (c) invading bristle lumen and two mechanoreceptive dendrites $(m)$ proximally attached to base. Each mechanoreceptive ending has an electrondense tubular body; some dense granules lie between scolopale and dendritic membranes. $a m$, articulating membrane; es, extra-cellular space. $\times 13000$

of the bristle shaft is somewhat similar to the "4-group" setae: The dendrites are bathed in an electron-dense fluid and surrounded by a thin, irregular-shaped scolopale. Further distally the scolopale becomes thicker and attaches at one side to the cuticle wall (Fig. 12a). Again, we find a circular lumen containing unbranched dendrites and a crescent-shaped lumen filled by fluid of low density (Fig. 12 b). The crescent-shaped lumen becomes more and more reduced distally while the cuticle wall increases in thickness. In contrast to the " 4 -group" bristles, no pores are present in the hair shaft. Instead, close to the tip the circular lumen opens through a narrow slit to the outside (Inset in Fig. 12b). At this point the dendrites are extremely slender and contain only one microtubule.

\section{Other Bristles}

Several other tarsal bristles have been encountered in various cross-sections but were not studied systematically. Two "lateral" bristles, one located on each side of Haller's organ (Fig. 1), have two mechanoreceptive dendrites attached to the hair base and several dendrites which pass into the lumen (Fig. 13). All bristles on the ventral side of the tarsus contained dendrites in the lumen except for one seta which may have mechanoreceptors at the base. Some ventral 
bristles were observed to be of the same type as described for the "four-group" except that they had five dendrites rather than one or two. These results apparently do not agree with Lees' opinion (1948) that all ventral tarsal bristles are simply tactile.

\section{Discussion}

The following generalizations can be made from our findings on the sensilla of A. americanum and probably apply to other ixodid ticks: The tarsal setae are multi-innervated with several dendrites inside the lumen and often with two mechanoreceptive endings attached to the base. The bristle wall is usually perforated by an elaborate pore system or slit openings, providing a communication to the outside. Those properties are typical for chemoreceptors in many arthropods (Slifer, 1961; 1970) but have not been previously described in Acarina.

The existence of a mechanoreceptive dendrite in a chemoreceptor has been reported in tarsal and labellar hairs of the blow fly (Grabowski and Dethier, 1954; Larsen, 1962) and its presence has also been concluded from electrophysiological experiments (Wolbarsht and Dethier, 1958). However, no morphological details are known. It is especially interesting that the tick sensillum has two mechanoreceptive dendrites whereas most mechanoreceptors in arthropods are only singly innervated (Schwartzkopff, 1964; Bullock and Horridge, 1965). The fine structure of the two mechanoreceptive endings resembles closely those found in insect tactile hairs (Thurm, 1964; Richter, 1964; Moeck, 1968) and in spider bristles (Foelix, 1970a). While singly innervated tactile hairs are simple phasic mechanoreceptors, only indicating the change in position, a double innervation could provide further information such as the direction in which the bristle is bent. This possibility should be checked electrophysiologically.

The chemoreceptive dendrites can either ramify at the base while entering the bristle lumen or they may ascend the shaft without branching. In each case, openings in the cuticle wall establish a direct communication to the outside and this is the prerequisite for most chemoreceptors (including hygroreceptors). It is interesting that the additional mechanoreceptors occur only in bristles with a single opening at the tip but not in combination with a pore system in the cuticle wall. Because of the close resemblance to the tarsal hairs in the blow fly (Dethier, 1955; Adams et al., 1965) we propose that these thick-walled bristles with several unbranched dendrites, a single opening at the tip and two mechanoreceptors at the base, are contact chemoreceptors. Apparently this type sensillum has a dual function, serving as both mechano- and chemoreceptor.

The size and structure of the pores is typical for a specific bristle. The narrow slit-like pores as well as the "plugged" pores (Fig. 14) could be functionally interpreted as a protection device against water loss. It seems difficult, however, to explain the exact function of the ovoid body plugging one of the pore types. One might hypothesize a regulating (valve) function like the pits in the wall of certain plant cells, provided that this plug is movably suspended. It should be emphasized that these large "plugged" pores have not been previously reported in any insect or other arthropod sensilla.

The fine structure of the dendrites exhibits one remarkable deviation, namely the ciliary structure. Whereas the ciliary structure of dendrites in vertebrate and 

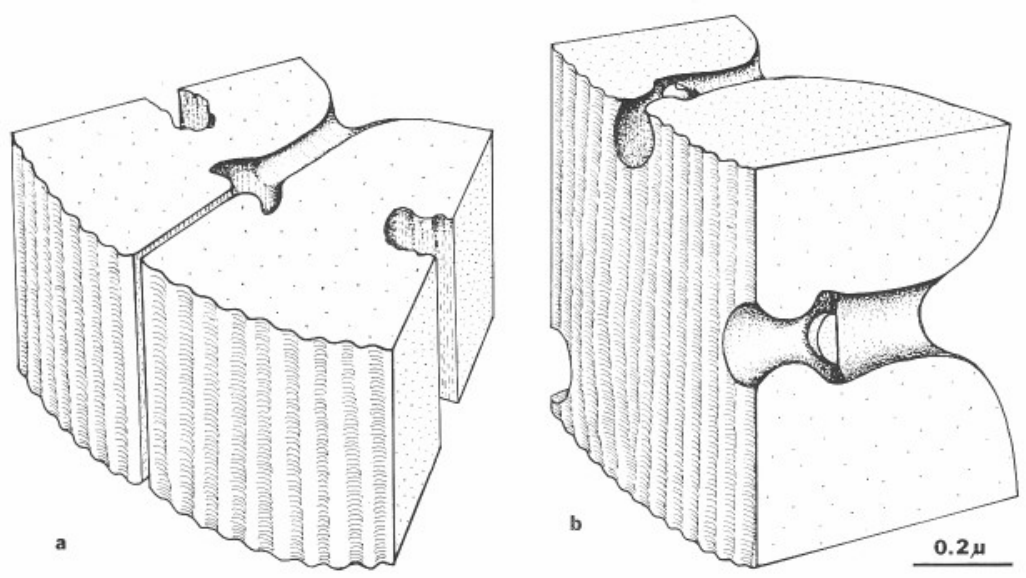

Fig. 14a and b. Cutaway view of two pore types found in tarsal tick sensilla. a) Narrow, slit-like pores expand into a heart-shaped column which sends cylindrical canals to the central lumen of the bristle. b) Large-sized pores with a lens-shaped, euticular body plugging the pore canal

invertebrate receptors consists of 9 peripheral double-tubules $(9+0$ or $9+2$; Afzelius, 1969), most tick sensilla possess 11 double-tubules without central elements $(11+0)$. Although there may be some variation $(9$ to 12$)$ the number found most frequently is 11 . The significance of this unique array remains an open question. To our knowledge the only other consistently modified ciliary structure known $(10+0)$ occurs in sensory organs of a parasitic nematode (Ross, 1967).

The arrangement of the various bristle groups described above is almost the same in adult forms of $A$. americanum and also in representatives of two other tick genera which were examined (Dermacentor variabilis, Haemaphysalis leporispalustris). An almost identical bristle type as described for the "four-group" has been reported in the mite Macrocheles muscaedomesticae (Coons, 1970). We therefore assume that the bristle types found in A. americanum represent common forms among the Acarina.

The histology of many arachnid sensory hairs was described by Gossel (1935). He observed two sensory cells supplying one tactile hair in a mite, but erroneously stated the same for a spider (Foelix, 1970a). Gossel also reported a presumably chemoreceptive hair type on the tarsus of a mite but could not demonstrate any connection to the outside. On the basis of either having a blunt or sharppointed tip, Zolotarev and Sinitsyna (1965) called the first type chemoreceptors, the latter mechanoreceptors. It seems, however, safer to investigate the actual innervation, as a blunt-tipped chemoreceptor can also be equipped with mechanoreceptors. Therefore, their conclusion that most common tarsal bristles are mechanoreceptors (except for the "four-group" and some blunt-tipped setae close to the pretarsus; see Fig. 2) is only in part correct. In our material most bristles show morphological evidence for chemoreceptors and many have additional mechanoreceptors, whereas plain mechanoreceptive hairs have not been found. 
Compared to other arthropod legs, ticks possess only a small number of setae on their tarsi. A spider tarsus, for instance, bears numerous bristles $(>200)$ but more than two thirds are simple mechanoreceptors and less than one third consists of a type of chemoreceptor (Foelix, 1970 b). However, the few bristles in ticks are particularly interesting because they possess either a combination of mechano- and chemoreceptors with a single slit opening at the tip or plain chemoreceptors with branching dendrites and a complex pore system in the cuticle wall.

\section{References}

Adams, J. R., Holbert, P. E., Forgash, A. J.: Electronmicroscopy of the contact chemoreceptors of the stable fly, Stomoxys calcitrans (Diptera: Muscidae). Ann. entomol. Soc. Amer. 58, 909-917 (1965).

Afzelius, B. A.: Ultrastructure of cilia and flagella. In: Handbook of molecular cytology, ed. by A. Lima-de-Faria, p. 1221-1242. Amsterdam: North Holland 1969.

Batelli, A.: Note anatomo-fisiologiche sugli Ixodini. Communicazione preventiva, part II. Mon. Zool. Ital., II, (1891) cit. Nuttall et al., (1908).

Bullock, T. H., Horridge, G. A.: Structure and function in the nervous systems of invertebrates. San Francisco and London: Freeman \& Co. 1965.

Coons, L. B.: Fine structure of selected organ systems of the mite Macrocheles muscaedomesticae (Acarina; Mesostigmata; Macrochelidae). Doct. thesis, N. C. State Univ., Raleigh, N.C. $(1970)$.

Dethier, V. G.: The physiology and histology of the contact chemoreceptor of the blowfly. Quart. Rev. Biol. 30, 348-371 (1955).

El-Ziady, S.: The behavior of Ornithodoros erraticus (Lueas, 1849), small form (Ixoidea, Argasidae), towards certain environmental factors. Ann. entomol. Soc. Amer. 51, 317-336 (1958).

Foelix, R. F.: Structure and function of tarsal sensilla in the spider Araneus diadematus. J. exp. Zool. 175, 99-124 (1970a).

- Chemosensitive hairs in spiders. J. Morph. 132, 313-334 (1970b).

Gossel, P.: Beiträge zur Kenntnis der Hautsinnesorgane und Hautdrüsen der Cheliceraten. Z. Morph. Ökol. Tiere 30, 177-205 (1935).

Grabowski, C. T., Dethier, V. G.: The structure of the tarsal chemoreceptors of the blowfly, Phormia regina Meigen. J. Morph. 94, 1-19 (1954).

Larsen, J. R.: The fine structure of the labellar chemosensory hairs of the blowfly, Phormia regina Meig. J. Insect. Physiol. 8, 683-691 (1962).

Lees, A. D.: The sensory physiology of the sheep tick, Ixodes ricinus L. J. exp. Biol. 25, 145-207 (1948).

Locke, M., Collins, J. V.: The structure and formation of protein granules in the fat body of an insect. J. Cell Biol. 26, 857-884 (1965).

Moeck, H. A.: Electron microscopic studies of antennal sensilla in the ambrosia beetle Trypodendron lineatum (Olivier) (Scolytidae). Canad. J. Zool. 46, 521-575 (1968).

Nuttall, G. H. F., Cooper, W. F., Robinson, L. E.: On the structure of Haller's organ in the Ixoidea. Parasitology 1, 238-243 (1908).

Palade, G. E.: A study of fixation for electron microscopy. J. exp. Med. 95, 285-297 (1952).

Richardson, K. C., Jarret, L. J., Finke, E. H.: Embedding in epoxy resins for ultrathin sectioning in electron microscopy. Stain Technol. 35, 313-323 (1960).

Richter, S.: Die Feinstruktur des für die Mechanorezeption wichtigen Bereichs der Stellungshaare auf dem Prosternum von Calliphora erythrocephala Mg. (Diptera). Z. Morph. Ökol. Tiere 54, 202-218 (1964).

Ross, M. M. R.: Modified cilia in sensory organs of juvenile stages of a parasitic nematode. Science 156, 1494-1495 (1967).

Sabatini, D. D., Bensch, K., Barrnett, R. J.: Cytochemistry and electron microscopy. The preservation of cellular ultrastructure and enzymatic activity by aldehyde fixation. J. Cell Biol. 17, 19-58 (1963). 
Schulze, P.: Úber die Hautsinnesorgane der Zecken, besonders über eine bisher unbekannte Art von Arthropodensinnesorganen, die Krobylophoren. Z. Morph. Ökol. Tiere 38, 379-419 (1942).

Schwartzkopff, J.: Mechanoreception. In: The physiology of insecta, ed. by M. Rockstein, p. 509-561. New York and London: Academic Press 1964.

Slifer, E. H.: The fine structure of insect sense organs. Int. Rev. Cytol. 11, 125-159 (1961).

- The structure of arthropod chemoreceptors. Ann. Rev. Entomol. 15, 121-142 (1970).

Thurm, U.: Mechanoreceptors in the cuticle of the honey bee: Fine structure and stimulus mechanism. Science 145, 1063-1065 (1964).

Venable, J. H., Coggeshall, R. E.: A simplified lead citrate stain for electron microscopy. J. Cell Biol. 25, 407-408 (1965).

Wolbarsht, M. L., Dethier, V. G.: Electrical activity in the chemoreceptors of the blowfly. I. Responses to chemical and mechanical stimulation. J. gen. Physiol. 42, 393-412 (1958).

Zolotarev, E. Kh., Elizarov, Yu. A.: Studies of chemoreception in insects and ticks. Location of the chemoreceptors in the tick Ixodes persulcatus P. Sch. Vestn. Mosk. Univ. 18, 7-9 (1963).

- Sinitsyna, Ye. Ye.: Chemoreceptive organs on the fore legs of ixodid ticks. Vestn. Mosk. Univ. 20, 17-25 (1965).

Dr. R. F. Foelix and Dr. R. C. Axtell

Dept. of Entomology, NCSU

P.O.B. 5215

Raleigh, N.C. $27607 /$ U.S.A. 